\title{
The Physical and Chemical Properties of Fine Carbon Particles-Pinewood Resin Blends and Their Possible Utilization
}

\author{
Aviwe Melapi, ${ }^{1,2}$ Sampson N. Mamphweli, ${ }^{1}$ David M. Katwire, ${ }^{2}$ and Edson L. Meyer ${ }^{1}$ \\ ${ }^{1}$ Institute of Technology, University of Fort Hare, Private Bag X1314, Alice 5700, South Africa \\ ${ }^{2}$ Department of Chemistry, University of Fort Hare, Private Bag X1314, Alice 5700, South Africa
}

Correspondence should be addressed to Aviwe Melapi; a.melapi@gmail.com

Received 17 October 2014; Revised 31 March 2015; Accepted 1 April 2015

Academic Editor: Kaustubha Mohanty

Copyright (C) 2015 Aviwe Melapi et al. This is an open access article distributed under the Creative Commons Attribution License, which permits unrestricted use, distribution, and reproduction in any medium, provided the original work is properly cited.

\begin{abstract}
The application of biomass gasification technology is very important in the sense that it helps to relieve the dwindling supply of natural gas from fossil fuels, and the desired product of its gasification process is syngas. This syngas is a mixture of $\mathrm{CO}$ and $\mathrm{H}_{2}$; however, by-products such as char, tar, soot, ash, and condensates are also produced. This study, therefore, investigated selected by-products recovered from the gasification process of pinewood chips with specific reference to their potential application in other areas when used as blends. Three samples of the gasification by-products were obtained from a downdraft biomass gasifier system and were characterized in terms of chemical and physical properties. FTIR analysis confirmed similar spectra in all charresin blends. For fine carbon particles- (soot-) resin blends, almost the same functional groups as observed in char-resin blends appeared. In bomb calorimeter measurements, $70 \%$ resin $/ 30 \%$ char blends gave highest calorific value, followed by $50 \%$ resin $/ 50 \%$ soot blends with values of $35.23 \mathrm{MJ} / \mathrm{kg}$ and $34.75 \mathrm{MJ} / \mathrm{kg}$ consecutively. Provided these by-products meet certain criteria, they could be used in other areas such as varnishes, water purification, and wind turbine blades.
\end{abstract}

\section{Introduction}

The need for renewable energy technology has drastically increased; this is made possible by its number of advantages over its disadvantages. Renewable energy technology is the use of energy sources that are continually replenished by nature. This energy can be produced from sun, wind, water, municipal waste, and plants. The renewable energy technologies convert these fuels into usable forms of energy which include the production of power, heat, and chemicals [1].

The techniques used in the conversion of the fuels to usable forms of energy are different and one of them is the biomass gasification technology. Out of these biomass gasification technologies, the fixed bed downdraft gasifier is more preferable due to low entrainment of particulates and lower tar content in the syngas as compared to other gasifier types [2]. The biomass material is mainly composed of cellulose, hemicellulose, lignin, and some extractives [3]. This material is used in a gasification process to generate electricity and heat. However, the biomass gasification technology is well defined as the process whereby a carbonaceous organic material is thermochemically broken down to yield syngas and some waste products. The syngas produced is a mixture of carbon monoxide, hydrogen, methane, carbon dioxide, nitrogen, and water vapour. However, the most important combustible constituents are carbon monoxide and hydrogen.

The process of biomass gasification is characterized by four different process steps that take place in the gasifier. The first step is the dehydration of the biomass feedstock, which occurs at a temperature range of $70^{\circ} \mathrm{C}$ to $200^{\circ} \mathrm{C}$. The feedstock material normally contains some amount of moisture that is less than $20 \%$, depending on the source and other conditions [4]. This is then followed by the pyrolysis, which occurs at a temperature range of $300^{\circ} \mathrm{C}$ to $600^{\circ} \mathrm{C}$. This is accompanied by the release of volatiles, tarry substances, and solid char. The third process step is the combustion zone where oxidation takes place, causing an increase in temperature from $700^{\circ} \mathrm{C}$ up to $1200^{\circ} \mathrm{C}$. The injected air introduces inert nitrogen, which later dilutes the syngas [5]. The last zone of the gasifier is the reduction zone. Here, the gases from the pyrolysis and combustion zones react with char to form the syngas. The combustible gases leave the gasifier at lower temperatures 
between $200^{\circ} \mathrm{C}$ and $500^{\circ} \mathrm{C}$. By-products are simultaneously produced as the syngas is formed from the gasification process. Among the by-products produced are the gasifier resin, carbon fine particles (soot), ash, condensates, and char. These by-products have a variety of applications. The char produced from the gasification process can be used in agriculture as a soil amendment. Char is also used in rubber tyre industries as an additive, in water and gas purification, and in the removal of tar from a gasification process. Resin is used as an adhesive. Resin is also used in circuit boards and in varnishes.

Studies conducted by Klinghoffer in 2013 suggested that char from a biomass gasification plant can be used in catalytic applications for tar reforming [6]. This process is beneficial because it addresses the issue of tar destruction and the issue of char disposal or utilization. One of the main challenges with catalytic methods of tar decomposition is the rapid deactivation of the catalyst [6]. Abu El-Rub et al. in 2004 conducted a study on the catalytic performance of commercial biomass char produced from the pyrolysis of pinewood in comparison with that of conventional tar reforming catalyst such as nickel, dolomite, and olivine, for reforming of naphthalene and phenol, which are tar surrogates. The study established that, with the char catalyst, the conversion of phenol at $700^{\circ} \mathrm{C}$ was almost twice as much as that which was obtained using the olivine catalyst. The conversion with dolomite and nickel catalysts was achieved at approximately $90 \%$ and the conversion with char was at $81.6 \%$ efficiency. With naphthalene, almost $100 \%$ conversion efficiency was achieved with the char catalyst at $900^{\circ} \mathrm{C} .100 \%$ conversion efficiency was obtained with the nickel catalyst at the same condition under which naphthalene was used, and conversion was $55 \%$ and $61 \%$ with olivine and dolomite, respectively [7]. Studies by Wang et al. in 2011 also showed that char can be an effective catalyst support for synthesis gas cleanup. Using benzene as a tar surrogate, they achieved $30 \%$ conversion with char at $900^{\circ} \mathrm{C}$. After mixing $\mathrm{NiO}$ with char at a nickel loading of $20 \mathrm{wt} \%$, over $80 \%$ of benzene removal was achieved at the same temperature [8]. Another study conducted by Min et al. in 2011 also used char and char supported iron catalyst for steam reforming of tar from biomass gasification [9]. These studies demonstrate that char from a biomass gasification plant has a catalytic effect for tar destruction.

Tar generated from the air gasification of woody biomass in a two-stage gasifier was studied by Mun et al. in 2011 [10]. They measured the presence of single ring aromatics, including toluene, benzene, and styrene; 2-ring aromatics, including naphthalene, indene, and methyl naphthalene; and 3- and 4-ring aromatics, including phenanthrene and acenaphthylene as well as oxygenated compounds such as dibenzofuran and phenol.

Formation of fine carbon particles (soot) is a very complex phenomenon involving both homogeneous and heterogeneous processes; however, it may act as a condensation nucleus of polyaromatic hydrocarbons (PHAs) and other organic substances and can also be used as a possible $\mathrm{NO}_{x}$ reduction agent apart from its undesired effect of generating solid deposits in gas engines [11, 12]. The formation of soot implies a number of complex physical and chemical processes that controls the conversion of gaseous fuel into solid particles that are not well understood [13]. Soot can react with several gases such as $\mathrm{O}_{2}, \mathrm{CO}_{2}$, or $\mathrm{H}_{2} \mathrm{O}$ and can be gasified; its reactivity to these gases is directly related to its structure and composition [14]. Surface area, particle size, and crystallinity are among the properties that affect soot particle reactivity, and its nanostructure depends on its formation conditions, like fuel origin, residence time, and temperature as understanding these types of dependency is fundamental to control the physical properties of the soot and, therefore, its chemical reactivity [15-18]. De Soete in 1988 used soot as gasification feedstock and reported that there was a negligible reaction with $\mathrm{H}_{2} \mathrm{O}$ below $527^{\circ} \mathrm{C}$ and that the major product obtained at higher temperature was $\mathrm{CO}$ [19].

When these by-products of gasification are blended, a possible synergistic effect may arise during their further application in other process steps. The blending of resin with char or soot could enhance the chemical and physical properties of both samples. The blended materials can also be further used as gasification feedstocks for syngas production. However, very limited data is available in the literature detailing the use of gasification by-products as blends in other process applications. This study, therefore, sought to investigate the possibility of blending selected by-products of gasification with a view to characterize them so as to establish their potential applications in other areas when used as blends.

\section{Materials and Method}

2.1. Experimental Procedure for Generation of By-Products. The pinewood material dumped by a nearby sawmill industry was used to feed the downdraft gasifier situated at Melani village, Eastern Cape Province of South Africa. Before feeding into the gasifier, the raw pinewood was cut into blocks with a size range of $\sim 8 \mathrm{~cm} \times 8 \mathrm{~cm} \times 4 \mathrm{~cm}$. Pinewood was used for the experiment because of its availability as compared to other biomass feedstocks and because a homogeneous starting material needs to be obtained as this allows for better comparison of different reaction conditions. However, in comparison to other biomass feedstocks, pinewood has a relatively higher calorific value $(19 \mathrm{MJ} / \mathrm{kg})$ and a low sulphur content $(0.02 \%$ of dry wt.) which allows for less emission of $\mathrm{SO}_{2}$ that is a source of acid rain [20].

The blocks were loaded into the reactor at a rate of $\sim 107 \mathrm{~kg} / \mathrm{hr}$. The temperature of the combustion zone of the downdraft gasifier system was in the range of $1200^{\circ} \mathrm{C}$ and $1500^{\circ} \mathrm{C}$, which allows for the disintegration of some quantities of tar produced during the gasification process. The downdraft gasifier is designed to tolerate feedstock with moisture content of less than $20 \%$, although it can also accommodate feedstock moisture content of up to $25 \%$.

The composition of the by-products produced in a gasification process is dependent on the type of gasification system employed and the type of feedstock used [20]. Table 1 presents the compositional analysis of the pinewood used as feed material for the gasification process used to recover the byproducts. 
TABLE 1: The composition of pinewood in terms of proximate and ultimate analyses.

\begin{tabular}{|c|c|c|c|}
\hline \multicolumn{2}{|c|}{ Proximate analysis } & \multicolumn{2}{|c|}{ Ultimate analysis } \\
\hline Properties & $\begin{array}{c}\text { Composition } \\
\text { (wt\%) }\end{array}$ & Element & $\begin{array}{c}\text { Composition } \\
(\mathrm{wt} \%)\end{array}$ \\
\hline Moisture content & 15.2 & $\mathrm{C}$ & 50.6 \\
\hline Volatile matter content & 70.2 & $\mathrm{O}$ & 22.2 \\
\hline Ash content & 5.92 & $\mathrm{H}$ & 6.3 \\
\hline Fixed carbon & 8.41 & $\mathrm{~N}$ & 0.3 \\
\hline
\end{tabular}

2.2. Sample Collection and Preparation. During the gasification process, some quantities of char, resin, soot, ash, and condensates were produced as by-products. Of these, three samples which included the gasifier char, resin, and soot were collected in sample bottles for analysis. The scrubber soot is a black collection of fine carbon particles found on top of the scrubber water in the cooling pond. The char is incompletely combusted material found in the char compartment part of the gasifier. The gasifier resin is a sticky material produced during devolatilisation stage of the gasification process; this was collected from the condensate tank. The samples were collected and prepared randomly in blends of $30 \%$ resin $/ 70 \%$ char, $50 \%$ resin $/ 50 \%$ char, and 70 resin $/ 30 \%$ char. These blend ratios were randomly chosen without recourse to standard ratios from the literature. The reason for blending was to establish their combined effect when used in other applications.

2.3. Material Characterization. To determine the usefulness of a material requires an understanding of its properties and composition, and the steps taken to establish their potential use in other areas began with the characterization of such material using different analytical techniques. The samples used for this study were characterized using Fourier Transform Infrared (FTIR) and oxygen calorimeter. These are the most important analytical instruments when attempting to predict or describe the application of gasification byproducts based on their composition and properties.

2.3.1. Heating Value Measurements. An oxygen bomb calorimeter $(\mathrm{Eco} \mathrm{Cal} 2 \mathrm{~K})$ was used to measure the heating value of the pure and blended samples of the by-products. The calorimeter was first calibrated with a $0.5 \mathrm{~g}$ of benzoic acid $\left(\mathrm{C}_{7} \mathrm{H}_{6} \mathrm{O}_{2}\right)$ before measurements were taken. About $1 \mathrm{~g}$ of each sample was weighed using a watch glass. The weighed samples were then transferred into a crucible in the outer electrode connected to the lid of the vessel. The vessel was then pressurized up to $3000 \mathrm{kpa}$ using oxygen gas. The vessel was then taken into the calorimeter for firing to take place. For each mass of the sample input in the calorimeter, the heating value was measured in units of $\mathrm{MJ} / \mathrm{kg}$.

2.3.2. FTIR Analysis of Pure and Blended Samples. Fourier Transform Infrared (FTIR) spectroscopy is a technique used to obtain an infrared spectrum of absorption, emission, and photoconductivity [21]. FTIR (Perkin Elmer 2000 system)

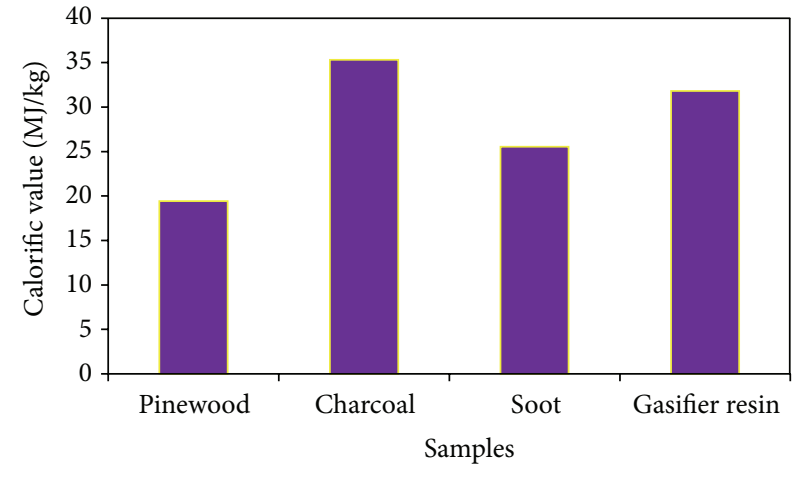

FIGURE 1: Calorific value of pure samples of gasification by-products.

was used in this study to observe the absorption bands of the pure and blended by-products. The by-products were ground to fine powder and mixed with potassium bromide $(\mathrm{KBr})$ powder in order to form samples that were transparent to FTIR. The samples were then inserted into FTIR spectroscopy and spectra recorded over the range of 400 to $4000 \mathrm{~cm}^{-1}$ at a resolution of $2 \mathrm{~cm}^{-1}$. The samples were pressed with $\mathrm{KBr}$ powder before the FTIR analysis because of its inert nature. It does not react with the samples to be analysed and helps in better peak resolution since it does not show absorbance in the infrared region of the spectrum.

\section{Results and Discussion}

3.1. Calorific Value of the Materials. The heating values, also known as calorific value or energy value of the pure and blended materials, were determined using a CAL $2 \mathrm{~K}$ oxygen calorimeter. This was undertaken in order to determine the energy content of the gasification by-products and to compare them with that of their blends so as to be able to predict their potential application in other process steps.

The calorific values of pure samples of the gasification byproducts are presented in Figure 1.

In Figure 1, it can be clearly seen that the calorific values of the by-products are higher than the pinewood (19.4 MJ/Kg) used as feedstock for the gasification process. However, there is a significant difference in calorific value of the by-products as also evident in Figure 1. The higher calorific value for char $(\sim 35.3 \mathrm{MJ} / \mathrm{Kg})$, which is comparable with good quality coal, is due to low ash yields from partially combusted pinewood material. The formation of char is largely contributed by lignin, while cellulose contributes to formation of volatile matter [22]. The volatile matter is removed during gasification leaving the lignin behind, which then results in a high calorific value of the char. The calorific value of any material in a thermochemical process is hugely affected by moisture content and volatile matter as well as its ash content and elemental composition of the material [20]. The higher calorific values imply that the material can be used through direct burning or combustion for heat applications such as space heating. The higher energy per volume also makes the char more economical to transport. The calorific value 




FIgURE 2: The calorific values of blended samples of resin and char.

of the resin is approximately $31.8 \mathrm{MJ} / \mathrm{Kg}$. This difference in calorific value may be attributed to the quantity of carbon, which is higher in char than in resin. A $1 \%$ increase in carbon concentration will elevate the calorific value by approximately $0.39 \mathrm{MJ} / \mathrm{kg}$ [23]. The difference may also be attributed to a lower degree of oxidation. Resin contains some amount of water and some solid particles as well as hundreds of organic compounds that are highly oxygenated which plays a role in the reduction of its calorific value [14]. Soot has the lowest calorific value of $25.5 \mathrm{MJ} / \mathrm{Kg}$; this is due to the fact that most of the carbon reacted with oxygen to form carbon dioxide $\left(\mathrm{CO}_{2}\right)$ during gasification process.

Figure 2 also presents the calorific values of the resinchar mixtures, blended at 30\%/70\%, 50\%/50\%, and 70\%/30\% ratios. The essence of blending is to establish their combined effect when used in other process applications.

The calorific values of resin-char blends varied as the blends were mixed at different ratios. The sample with the highest calorific value $(35.86 \mathrm{MJ} / \mathrm{kg})$ is the $30 \% \mathrm{resin} / 70 \%$ char blend, compared to $33.82 \mathrm{MJ} / \mathrm{kg}$ and $35.23 \mathrm{MJ} / \mathrm{kg}$ for the $50 \%$ resin $/ 50 \%$ char and $70 \%$ resin $/ 30 \%$ char blends, respectively. This difference is attributed to the higher ratio of char in the blend as compared with other blends, as well as differences in chemical composition between char and resin. Char is a solid residue that is composed primarily of carbon while resin is a combination of single and multiring aromatics such as toluene, benzene, and styrene including methylated naphthalene as well as oxygenated compounds such as dibenzofuran and phenol and also contains a lot of water which lowers its calorific value $[6,10]$. The calorific value of the blend reduced significantly when the ratio of resin in the blend was increased from $30 \%$ to $50 \%$ with a reduction in the ratio of char from $70 \%$ to $50 \%$ (50\% resin/50\% char). This then follows the trend that calorific value reduces with increasing percentage of resin in the blend due to the reason presented earlier. The samples contain a significant amount of energy that would make them suitable to be converted into other forms of energy.

The calorific values of mixtures of resin-soot, blended at $30 \% / 70 \%, 50 \% / 50 \%$, and $70 \% / 30 \%$ ratios, are shown in Figure 3.

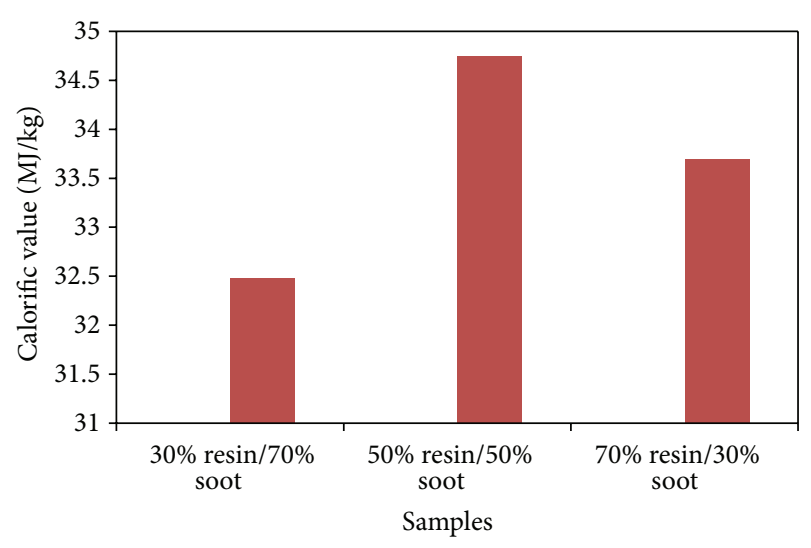

FIGURE 3: The calorific values of blended samples of resin and soot.

There is also a variation in the calorific values of the samples of resin-soot blends which is also attributed to the ratio of mixing. However, the blend of resin and soot with the highest calorific value is the $50 \%$ resin $/ 50 \%$ soot blend with the value of $34.75 \mathrm{MJ} / \mathrm{Kg}$. This is contrary to the resinchar blend which gave the highest calorific value with the $30 \%$ resin $/ 70 \%$ char blend, resulting in a calorific value of $35.86 \mathrm{MJ} / \mathrm{kg}$. $30 \%$ of resin blended with $70 \%$ of soot resulted in a calorific value of $32.48 \mathrm{MJ} / \mathrm{kg}$. When the quantity of resin in the blend was increased from $30 \%$ to $50 \%$, a calorific value of $34.75 \mathrm{MJ} / \mathrm{kg}$ was obtained. This calorific value dropped again to $33.7 \mathrm{MJ} / \mathrm{kg}$ when the quantity of resin in the blend was increased from $50 \%$ to $70 \%$. Soot is a solid material rich in carbon, and calorific value increases with an increase in the concentration of carbon [23], but inconsistency in the calorific values of the resin-soot blends is affected by the presence of resin in the blends because of the multiphase features that characterize resin. Despite the inconsistencies in the calorific values of the blends of resin and soot, they contain quite a reasonable quantity of energy that makes them good candidates as feedstock for energy production.

3.2. Functional Group Determination. The functional groups present in the pure by-products and their blends were determined to establish if blending could have an impact in the dominant chemical bonds and to also help determine their applications in other areas based on these functional groups. $\mathrm{R}$ refers to the gasifier resin while $\mathrm{S}$ and $\mathrm{C}$ refer to soot and char, respectively.

Figure 4 presents FTIR spectrum of pinewood.

Figures 4 and 5 present the FTIR spectra of pinewood and pure samples of the gasification by-products (soot, char, and resin). The unblended by-products are referred to as pure materials. These are presented for comparison purposes between the gasification feed material and the byproducts of the gasification process. Pinewood contains the $\mathrm{O}-\mathrm{H}$ group which appears in the region of $3400 \mathrm{~cm}^{-1}$ as evident in Figure 4. The presence of $\mathrm{O}-\mathrm{H}$ groups in the spectrum of pinewood explains the presence of moisture in the material $[21,22]$. The peak observed in the region of $2919 \mathrm{~cm}^{-1}$ corresponds to the $\mathrm{CH}$ stretching of $\mathrm{CH}_{2}$ and 


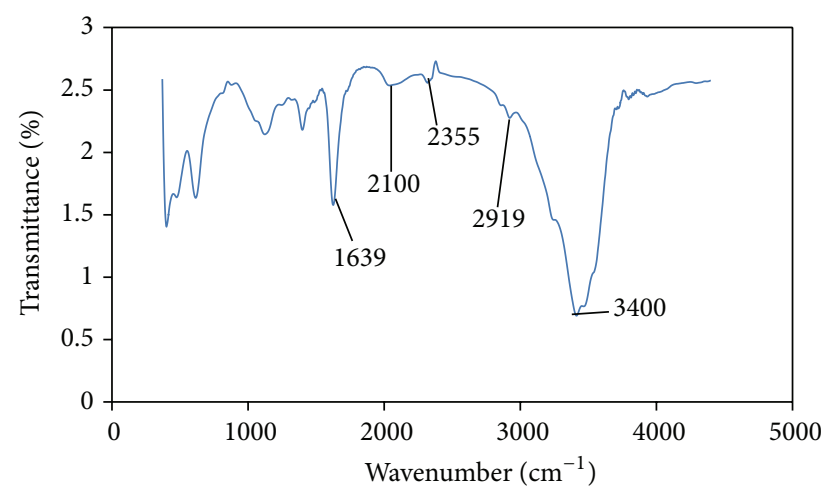

FIGURE 4: FTIR spectrum of pinewood.

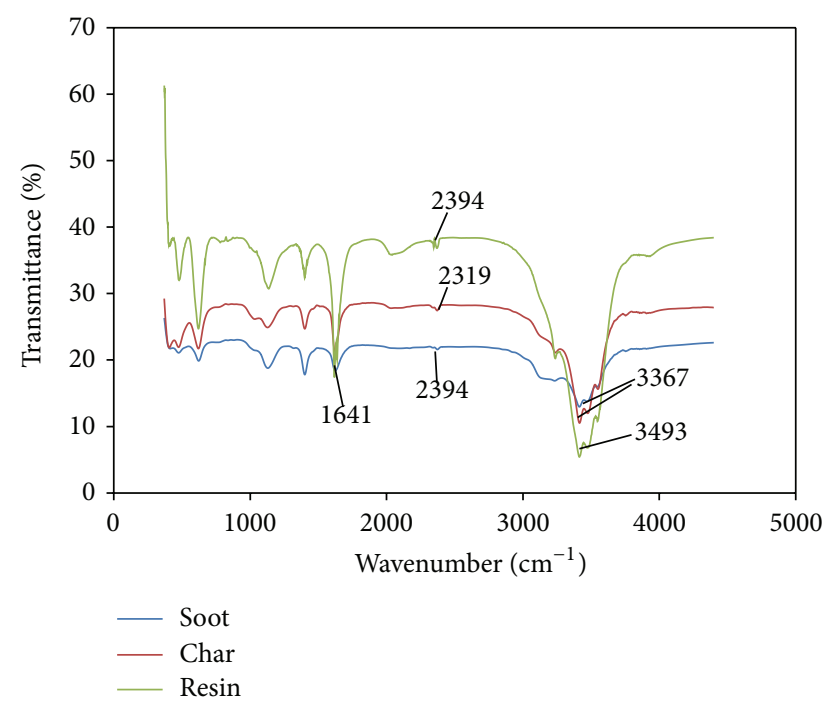

FIGURE 5: FTIR spectra of pure samples of gasification by-products.

$\mathrm{CH}_{3}$ of the lignocellulose structure; this is in agreement with existing literature [24]. The presence of $\mathrm{CO}_{2}$ is evident in the region of $2355 \mathrm{~cm}^{-1}$ [25]. The absorption peak around $2100 \mathrm{~cm}^{-1}$ reflects the presence of $\mathrm{C} \equiv \mathrm{C}$ even though the spectrum suggests that they are in minimal quantities; this observation could be due to contamination as this peak was not expected from pinewood. The absorption around $1639 \mathrm{~cm}^{-1}$ suggests the presence of the $\mathrm{C}=\mathrm{C}$ bonds due to lignin structure while the other groups such as $\mathrm{C}-\mathrm{N}$ and $\mathrm{C}-$ $\mathrm{O}$ appear in the fingerprint region of the spectrum. Figure 5 presents FTIR spectra of pure samples.

It can be noted from Figure 5 that the three by-products of gasification (resin, char, and soot) used for this study exhibited almost the same kind of functional groups with slight differences in absorption regions when compared to the pinewood used as feed material for the gasification process. However, the peak observed in the region of $3367 \mathrm{~cm}^{-1}$ for the char and soot spectra is due to the presence of $\mathrm{O}-\mathrm{H}$ which is attributed to the presence of moisture in the samples. For resin, the presence of the $\mathrm{O}-\mathrm{H}$ group was observed around $3493 \mathrm{~cm}^{-1}$, and the observation suggests higher moisture

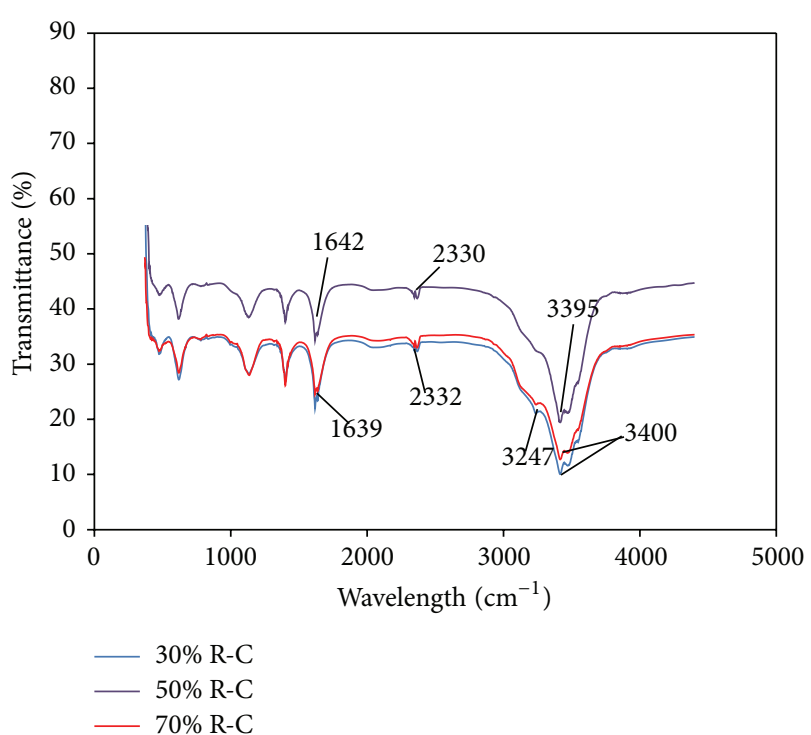

FIGURE 6: FTIR spectra of blended samples of gasification byproducts (resin and char blends).

content in the resin when compared to char and soot. This slight difference in the peak position of the $\mathrm{O}-\mathrm{H}$ group is due to the multicomponent mixture of different size molecules derived from depolymerisation and fragmentation of cellulose, hemicelluloses, and lignin component of the biomass feed material used for the gasification process. The absorption peaks at $2394 \mathrm{~cm}^{-1}$ and $2319 \mathrm{~cm}^{-1}$ reveal the traces of carbon dioxide. The $\mathrm{C}=\mathrm{C}$ which is present due to aromatic rings was observed within the region of $1641 \mathrm{~cm}^{-1}$. The bigger $\mathrm{C}=\mathrm{C}$ peak in the resin sample is due to the presence of the polycyclic aromatic hydrocarbons. The region below $1500 \mathrm{~cm}^{-1}$ is the fingerprint portion of the spectra. This region reflects the absorption of C-O, C-C vibrations [26].

The functional groups present in resin are an indication that it can be used as a raw material in the manufacture of plastics and fibres which are sources of aromatic polymers, through a single ring aromatic separation; however, this requires a high level of processing to separate the resin into its components since gasifier resins can contain hundreds of different components $[27,28]$. The results of the functional groups in char enable its use as a catalyst for the decomposition of hydrocarbons through cleavage of $\mathrm{C}-\mathrm{C}$ and $\mathrm{C}-\mathrm{H}$ bonds. This suggests that char may be a good catalyst for the decomposition of tar, while the $\mathrm{OH}$ radical in soot promotes its use in combustion systems for the production of energy where $\mathrm{CO}$ and $\mathrm{CO}_{2}$ are formed from the oxidation of soot. The by-products also confirmed the presence of water, carbon monoxide, alkenes, and alkanes, which allows their use as fertilizers and also in the production of industrial chemicals.

Figure 6 presents the FTIR spectra of resin-char blends, blended at $30 \% / 70 \%, 50 \% / 50 \%$, and $70 \% / 30 \%$ ratios.

The same kind of functional groups found in the samples of the pure materials could also be noticed with all the blends of resin and char. The presence of these functional groups is an indication that the blends of the by-products may be useful 

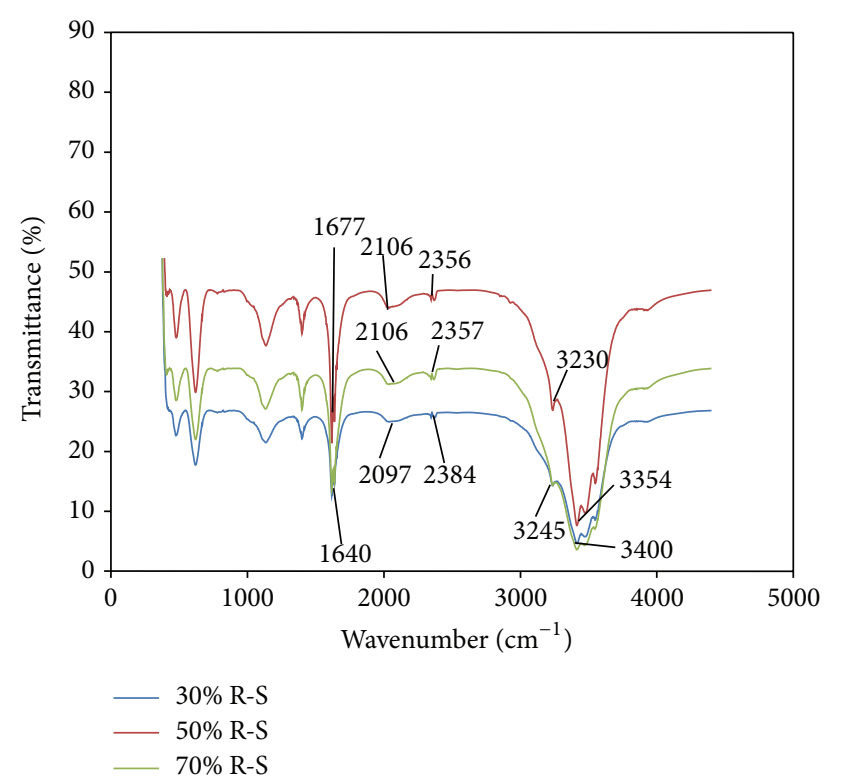

FIGURE 7: FTIR spectra of blended samples of resin and soot.

as a catalyst for the production of chemical compounds and the decomposition of tar as previously stated.

Figure 7 presents FTIR spectra of resin-soot blends, blended at $30 \% / 70 \%, 50 \% / 50 \%$, and $70 \% / 30 \%$ ratios.

The FTIR spectra of the blended by-products shown in Figures 6 and 7 for resin-char and resin-soot mixtures revealed the presence of $\mathrm{O}-\mathrm{H}, \mathrm{C}-\mathrm{C}, \mathrm{C}=\mathrm{C}, \mathrm{C}-\mathrm{O}$, and $\mathrm{C}-\mathrm{H}$ major functional groups while small quantities of $\mathrm{C} \equiv \mathrm{C}$ and $\mathrm{CO}_{2}$ were also observed. The wavenumber range at which these functional groups appear has been previously discussed in Figure 5. The observation of these peaks was due to the fact that all the blends of the by-products emanated from pinewood chips that are primarily composed of lignocellulose structure. The blends have exhibited almost the same peaks as those of the pure materials; this implies that the blending did not change the characteristics of the pure materials. The FTIR was useful in confirming that the blending of the gasification by-products under study does not change their functional groups composition. It also assisted in identifying the functional groups in order to determine the possible use of the by-products.

\section{Conclusion}

The by-products of the gasification of pinewood blocks retained the same functional groups as those of their parent material used for the gasification process, but only with a slight shift in the absorption regions of the spectra. The FTIR was found useful in identification of the functional groups of the studied by-products in order to determine the possible applications of the blends. The higher calorific values of the blends also make them good candidates as feedstocks for energy production. However, results obtained indicated that the blends of resin and char are much better to be used in other process applications than those of the resin and soot due to higher carbon concentration although the results did not differ significantly. The blending of the materials provided a medium for compositional exchange which ultimately resulted in strengthened blends. Since the production of syngas from the gasification process requires high or moderate feed calorific value and relatively high carbon concentration, then the higher contents of carbon in resin-char blends imply that the blends could be used as gasification feedstocks. Regasification of these by-products will reduce levels of pollution and toxic sulphur emissions to the environment. These materials could be used in other areas provided they meet certain requirements, that is, in terms of quality, safety, and so forth.

Since the characteristics of the three blending ratios (30\%/70\%, 50\%/50\%, and 70\%/30\%) have been determined, then a need to investigate the characteristics of the blending ratios that were omitted in this paper is recommended.

\section{Conflict of Interests}

The authors declare that there is no conflict of interests regarding the publication of this paper.

\section{Acknowledgments}

The authors wish to acknowledge Mr. Anthony Anukam for his immense and valuable contribution towards this paper. The research was also supported by the National Research Foundation (NRF) and the Fort Hare Institute of Technology (FHIT) in form of funding provided and their support is gratefully acknowledged.

\section{References}

[1] J. J. Hernández, R. Ballesteros, and G. Aranda, "Characterisation of tars from biomass gasification: effect of the operating conditions," Energy, vol. 50, no. 1, pp. 333-342, 2013.

[2] P. Dutta, V. Pandey, A. Das, S. Sen, and D. Baruah, "Down draft gasification modelling and experimentation of some indigenous biomass for thermal applications," Energy Procedia, vol. 54, pp. 21-34, 2014.

[3] F. Collard and J. Blin, "A review on pyrolysis of biomass constituents: mechanisms and composition of the products obtained from the conversion of cellulose, hemicelluloses and lignin," Renewable and Sustainable Energy Reviews, vol. 38, pp. 594-608, 2014.

[4] N. S. Mamphweli and E. L. Meyer, "Implementation of the biomass gasification project for community empowerment at Melani village, Eastern Cape, South Africa," Renewable Energy, vol. 34, no. 12, pp. 2923-2927, 2009.

[5] C. Dejtrakulwong and S. Patumsawad, "Four zones modeling of the downdraft biomass gasification process: effects of moisture content and air to fuel ratio," Energy Procedia, vol. 52, pp. 142149, 2014.

[6] N. Klinghoffer, Utilization of char from biomass gasification in catalytic applications [Ph.D. thesis], Columbia University, 2013.

[7] Z. Abu El-Rub, E. A. Bramer, and G. Brem, "Review of catalysts for tar elimination in biomass gasification processes," Industrial \& Engineering Chemistry Research, vol. 43, no. 22, pp. 6911-6919, 2004. 
[8] D. Wang, W. Yuan, and W. Ji, "Char and char-supported nickel catalysts for secondary syngas cleanup and conditioning," Applied Energy, vol. 88, no. 5, pp. 1656-1663, 2011.

[9] Z. Min, P. Yimsiri, M. Asadullah, S. Zhang, and C.-Z. Li, "Catalytic reforming of tar during gasification. Part II. Char as a catalyst or as a catalyst support for tar reforming," Fuel, vol. 90, no. 7, pp. 2545-2552, 2011.

[10] T.-Y. Mun, J.-O. Kim, J.-W. Kim, and J.-S. Kim, "Influence of operation conditions and additives on the development of producer gas and tar reduction in air gasification of construction woody wastes using a two-stage gasifier," Bioresource Technology, vol. 102, no. 14, pp. 7196-7203, 2011.

[11] M. Ambrogio, G. Saracco, V. Specchia, C. van Coen, M. Makkee, and J. A. Moulijn, "On the generation of aerosol for diesel particulate filtration studies," Separation and Purification Technology, vol. 27, no. 3, pp. 195-209, 2002.

[12] R. Bilbao, A. Millera, and M. U. Alzueta, "Influence of the temperature and oxygen concentration on NOx reduction in the natural gas reburning process," Industrial and Engineering Chemistry Research, vol. 33, no. 11, pp. 2846-2852, 1994.

[13] G. Chen, Y. Zhang, J. Zhu, Y. Cao, and W. Pan, "Coal and biomass partial gasification and soot properties in an atmospheric fluidized bed," Energy and Fuels, vol. 25, no. 5, pp. 19641969, 2011.

[14] Y. Chhiti, Non catalytic steam gasification of wood bio-oil [Ph.D. thesis], Institute National Polytechnique de Toulouse, 2011.

[15] R. L. Vander Wal and A. J. Tomasek, "Soot nanostructure: dependence upon synthesis conditions," Combustion and Flame, vol. 136, no. 1-2, pp. 129-140, 2004.

[16] L. E. Murr and K. F. Soto, "A TEM study of soot, carbon nanotubes, and related fullerene nanopolyhedra in common fuel-gas combustion sources," Materials Characterization, vol. 55, no. 1, pp. 50-65, 2005.

[17] W. J. Grieco, J. B. Howard, L. C. Rainey, and J. B. V. Sande, "Fullerenic carbon in combustion-generated soot," Carbon, vol. 38 , no. 4, pp. 597-614, 2000.

[18] H. Werner, D. Herein, J. Blöcker et al., "Spectroscopic and chemical characterisation of 'fullerene black'," Chemical Physics Letters, vol. 194, no. 1-2, pp. 62-66, 1992.

[19] G. De Soete, "Catalysis of soot combustion by metal oxides," in Proceedings of the Western States Section Meeting, The Combustion Institute, Salt Lake City, Utah, USA, March 1988.

[20] A. Anukam, S. Mamphweli, E. Meyer, and O. Okoh, "Computer simulation of the mass and energy balance during gasification of sugarcane bagasse," Journal of Energy, vol. 2014, Article ID 713054, 9 pages, 2014.

[21] S. Gaqa, S. Mamphweli, D. Katwire, and E. Meyer, "Synergistic evaluation of the biomass/coal blends for co-gasification purposes," International Journal of Energy and Environment, vol. 5, pp. 251-256, 2014.

[22] R. Rajarao, I. Mansuri, R. Dhunna, R. Khanna, and V. Sahajwalla, "Characterisation of gas evolution and char structural change during pyrolysis of waste CDs," Journal of Analytical and Applied Pyrolysis, vol. 105, pp. 14-22, 2014.

[23] F. A. López, T. A. Centeno, I. García-Díaz, and F. J. Alguacil, "Textural and fuel characteristics of the chars produced by the pyrolysis of waste wood, and the properties of activated carbons prepared from them," Journal of Analytical and Applied Pyrolysis, vol. 104, pp. 551-558, 2013.

[24] N. Q. Bui, P. Fongarland, F. Rataboul et al., "FTIR as a simple tool to quantify unconverted lignin from chars in biomass liquefaction process: application to SC ethanol liquefaction of pine wood," Fuel Processing Technology, vol. 134, pp. 378-386, 2015.

[25] T. Gougousi, D. Niu, R. W. Ashcraft, and G. N. Parsons, "Carbonate formation during post-deposition ambient exposure of high-k dielectrics," Applied Physics Letters, vol. 83, no. 17, pp. 3543-3545, 2003.

[26] B. M. Jenkins, O. Kitani, and C. W. Hall, "Physical properties of biomass," in Biomass Handbook, chapter 5.2, Gordon \& Bearch, New York, NY, USA, 1989.

[27] M. John, Organic Chemistry, Thomson Learning Academic Resource Centre, 7th edition, 2008.

[28] H. H. Schobert and C. Song, "Chemicals and materials from coal in the 21st century," Fuel, vol. 81, no. 1, pp. 15-32, 2002. 

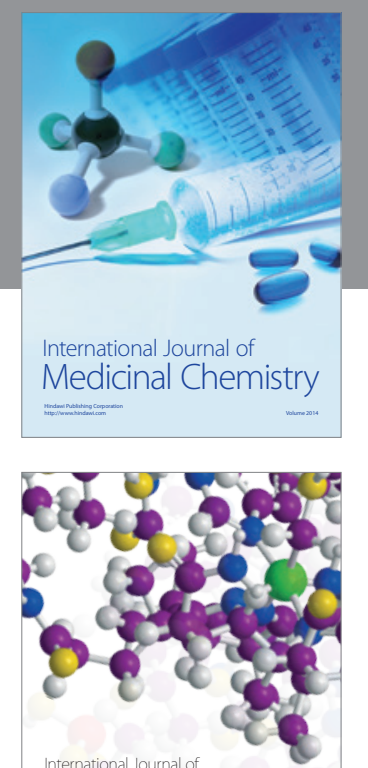

\section{Carbohydrate} Chemistry

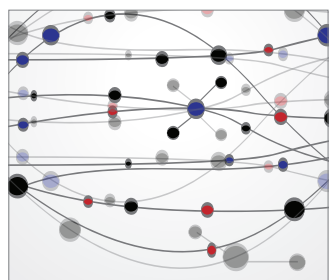

The Scientific World Journal
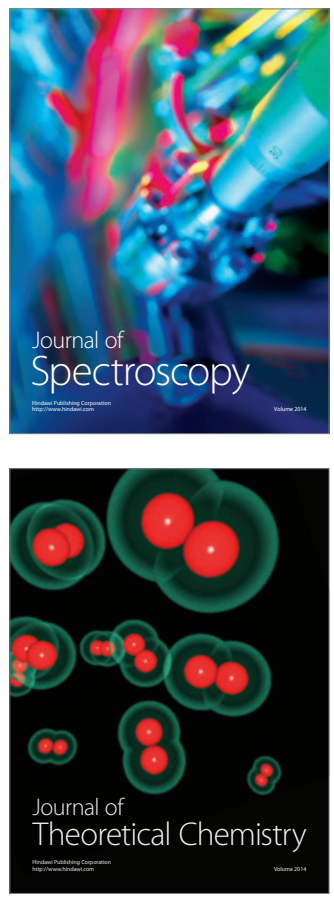
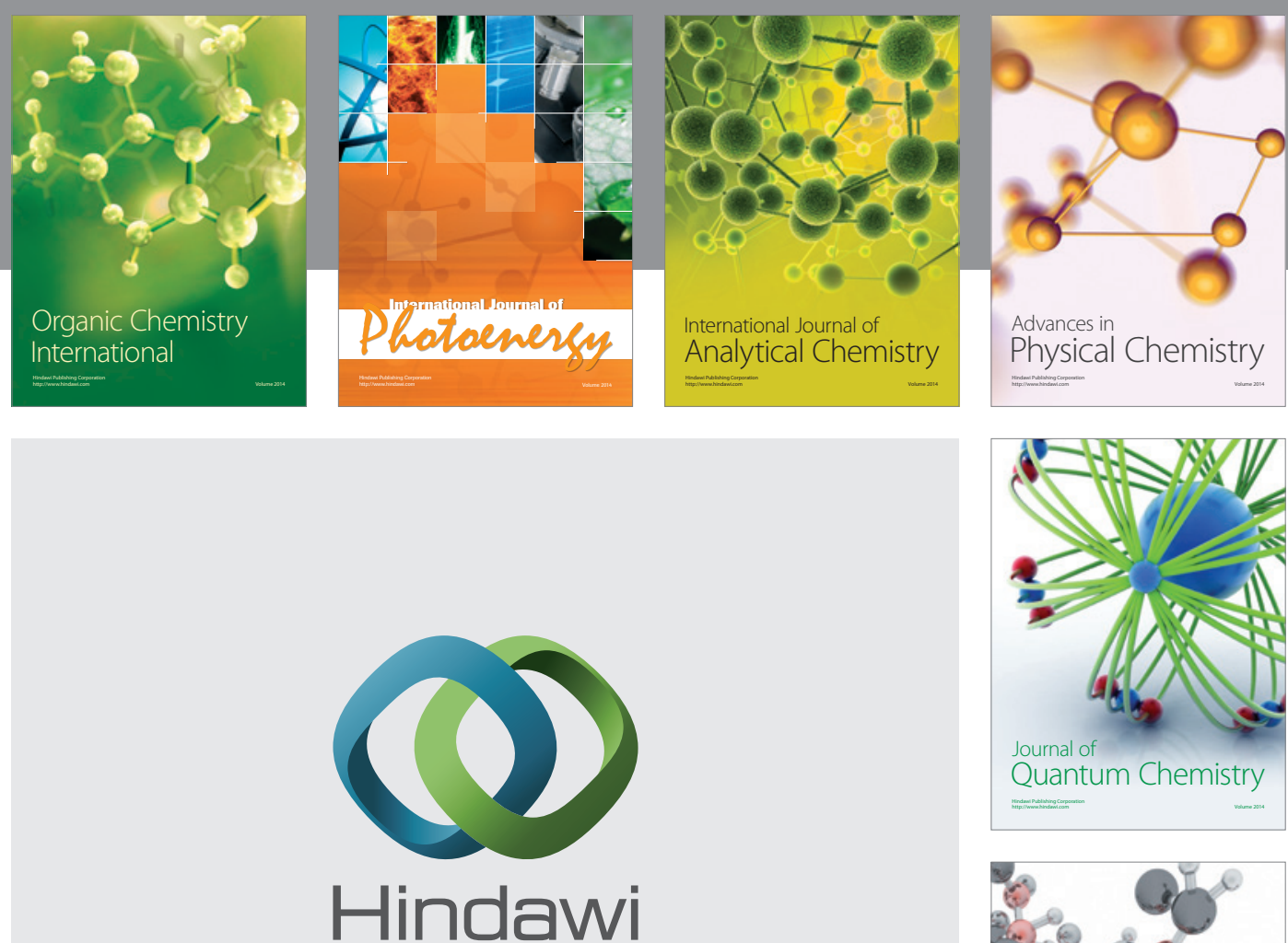

Submit your manuscripts at

http://www.hindawi.com

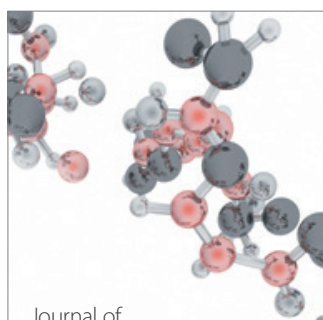

Analytical Methods

in Chemistry

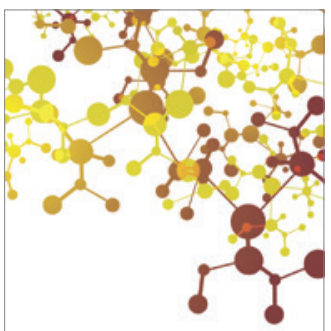

Journal of

Applied Chemistry



Inorganic Chemistry
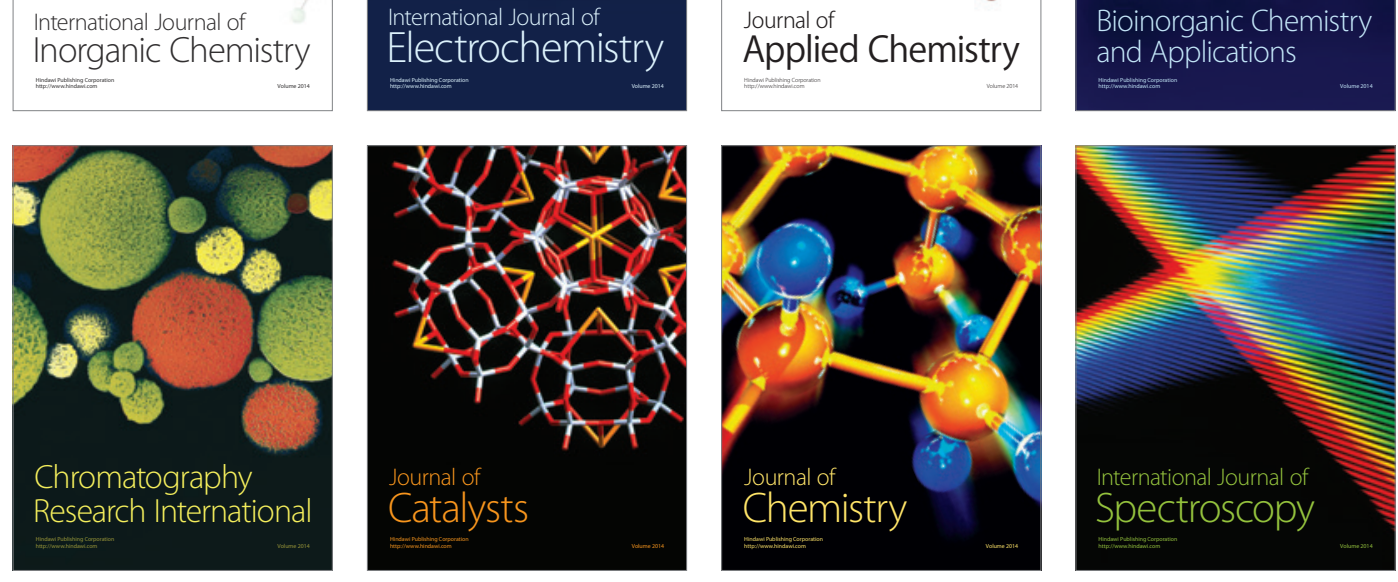